\title{
NGHIÊN CỨU CÁC THÔNG SỐ ẢNH HƯởNG ĐẾN LỰC HÁI TRÁI CÀ PHÊ CỦA MÁY THU HOẠCH CÀ PHÊ TẠI TỈNH ĐẮK LẮK
}

\author{
CHÂU MINH QUANG, NGUYẼ̃N VÕ TIẾN \\ Khoa Co Khí, Truờng Đại học Công nghiệp thành phố Hồ Chí Minh;
}

chauminhquang@iuh.edu.vn

Tóm tắt. Bài báo này trình bày nghiên cứu các thông số ảnh hưởng đến lực hái trái cà phê tươi của máy thu hoạch cà phê công nghiệp sử dụng rung động của các thanh hái. Căn cứ trên kết quả thực nghiệm trên thiết bị thí nghiệm kéo nén Instron 5544 Testing Machine để xác định được lực kéo đứt cuống trái cà phê tươi. Thiết kế, chế tạo mô hình hái trái cà phê dựa trên các yếu tố ảnh hưởng đến việc tạo ra lực hái. Đồng thời chế tạo một thiết bị đo lực để đo các lực được tạo ra trên mô hình máy hái cà phê. Trong quá trình thực nghiệm lần lượt thay đổi các thông số ảnh hưởng đến việc tạo ra lực hái cà phê. Thực nghiệm để xác định sự ảnh hưởng của các thông số này.

Từ khóa: máy thu hoạch cà phê, thu hoạch cà phê

\section{RESEARCH ON FACTORS AFFECTING THE FORCE OF COFFEE HARVESTING MACHINE IN DAK LAK PROVINCE}

\begin{abstract}
In Vietnam there are no studies about coffee picking fruit fresh forces. This paper presents the study of parameters affecting the capacity of picking fruit fresh coffee harvest coffee machines use vibrations of the bars picking. Based on experimental results on the device pull thereby determining traction off the left stalk of fresh coffee. Fabrication coffee fruit pickers model based on foreign designs define the parameters affect the momentum built up over the model. Also making its instrumentation to measure the forces generated on picking coffee machine models. In the measurement process in turn change the parameters affecting its creation. Experimental planning to determine the optimal parameters for coffee harvesters.
\end{abstract}

Key words: coffee harvesters, coffee harvesting machine

\section{GIỚI THIỆ}

Việt Nam đứng thứ hai trong nền công nghiệp xuất khẩu cà phê trên thế giới. Tuy nhiên, hiện nay cách thu hoạch cà phê ở Việt Nam hoàn toàn là thủ công, vẫn cần phải sử dụng nhiều nhân công, tuy đã có máy thu hoạch cầm tay nhưng năng suất thu hoạch vẫn không cải thiện đáng kể.

Hiện nay tại Việt Nam chưa nơi nào sử dụng máy thu hoạch cà phê công nghiệp, chưa có công trình nghiên cứu về lực hái trái cà phê tại Việt Nam nói chung và tại tỉnh Đắk-Lắk nói riêng nhằm tạo năng suất thu hoạch và chất lượng sau thu hoạch cao. Trên máy hái cà phê công nghiệp nếu lực hái không phù hợp sẽ dẫn đến năng suất kém hoặc ảnh hưởng đến chất lượng và sản lượng cà phê do bị gảy cành, rụng lá. Cần xác định lực hái cà phê phù hợp vì thổ nhưỡng từng vùng miền khác nhau, canh tác cũng không giống nhau có thể dẫn đến độ dai của cuống trái cà phê sẽ không giống nhau dẫn đến lực hái trái cà phê khác nhau khi sử dụng máy hái cà phê công nghiệp. Trên thế giới hiện nay đã có rất nhiều công trình nghiên cứu máy thu hoạch cà phê dạng công nghiệp.

Máy thu hoạch cà phê do $\mathrm{D}$. O. Mbuge and $\mathrm{P}$. K. Langat thiết kế [1] sử dụng máy rung động cơ học để thu hoạch cà phê. Về lý thuyết, một cây cà phê được coi như chùm dầm công xôn với khối lượng tập trung ở đầu. Tạo dao động cưởng bức lên cây để xác định sự kết hợp tần số, biên độ tối ưu nhằm thu hoạch hầu hết quả cà phê. Máy thu hoạch cà phê do Nat Jaques [2] và anh trai thiết kế và được nhà máy đóng tàu tại Úc chế tạo thành công vào năm 1986. Tại Úc, Nat và Dick Jaques là những nông dân đầu tiên nhận ra việc cơ khí hóa thu hoạch. Máy thu hoạch cà phê do Victor M. Alexandrino Portable thiết kế [3]. Máy gồm các trục được điều khiển bởi một động cơ, và các trục xoay cuốn các quả hoặc các cành như người điều khiển di chuyển thiết bị dọc theo nhánh. Các rãnh xoắn được thiết kế để kéo trái cà phê đứt ra khỏi cành. Trái cà phê được thu gom bằng cách trải bạt trên mặt đất để gom các trái rơi. Máy thu hoạch cà 
phê do Roy Scudder thiết kế [4] dùng để thu hoạch các loại cây trồng như dâu, cà phê, máy thu hoạch có khung, có thể di chuyển máy hướng dọc theo một hàng của thân, máy bao gồm các cụm thanh rung được gắn trên khung, mỗi cụm thanh rung đó bao gồm một trục quay có thể xoay tự do được để lùa vào các hàng cây trong quá trình thu hoạch. Máy thu hoạch cà phê sử dụng máy rung điện từ của Fábio Lúcio Santos và các cộng sự [5] chủ yếu nghiên cứu ảnh hưởng của biên độ và tần suất rung lên đến hiệu quả thu hoạch cà phê.

Tất cả những nghiên cứu máy thu hoạch cà phê trên vẫn không thể ứng dụng tại Việt Nam. Đối với trái cà phê khi thu hoạch chủ yếu là lấy hạt cho nên việc các thanh hái rung đập vào bên ngoài trái là chấp nhận được. Do đó sử dụng máy hái cà phê có các thanh rung đập vào trái vẫn được coi là tối ưu cần được nghiên cứu tại Việt Nam.

\section{THIẾT KẾ CHẾ TẠO MÔ HÌNH MÁY THU HOẠCH CÀ PHÊ VÀ THIẾT BỊ ĐO LỰC}

Nguyên lý làm việc của mô hình máy thu hoạch cà phê: Động cơ 1 quay, qua khớp nối trục (2) làm trục (3) quay, qua bộ truyền bánh răng (4) có tỷ số truyền $\mathrm{i}=1$, truyền chuyển động cho bộ truyền đai (5) có tỷ số truyền $\mathrm{i}=0,5$ làm trục (6) quay, đến bộ truyền xích (7) và (8) có tỷ số truyền $\mathrm{i}=1$ làm cho hai quả lệch tâm quay. Do vị trí lắp hai quả lệch tâm là đối xứng và quay cùng chiều nên trong một vòng quay của trục dao động sẽ tạo ra hai ngẫu lực cùng độ lớn nhưng ngược chiều nhau. Dao động này truyền tới các thanh rung lắp trên trục rung làm cho chúng dao động theo, tạo ra lực đập để hái các quả cà phê. Trục rung (12) quay tự do. Như vậy, xác định được lực đánh cần thiết của các thanh rung phù hợp để có thể đánh rụng trái cà phê ra khỏi cành với tỉ lệ rụng cao nhất, không làm tổn hại đến cây cà phê như: gãy cành, rụng lá nhiều, bong tróc vỏ thân cây,...(Hình 1)

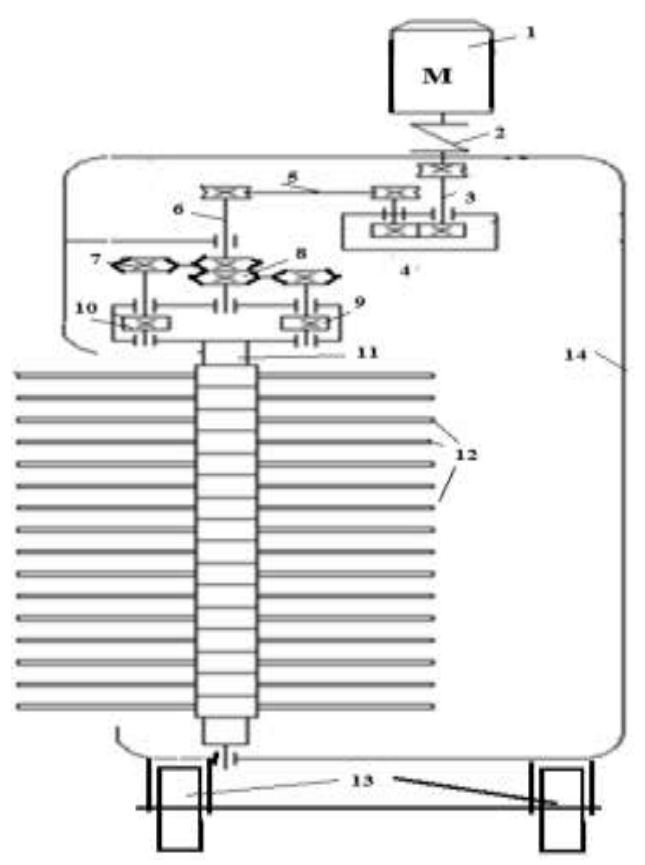

Hình 1: Sơ đồ nguyên lý máy thu hoạch cà phê

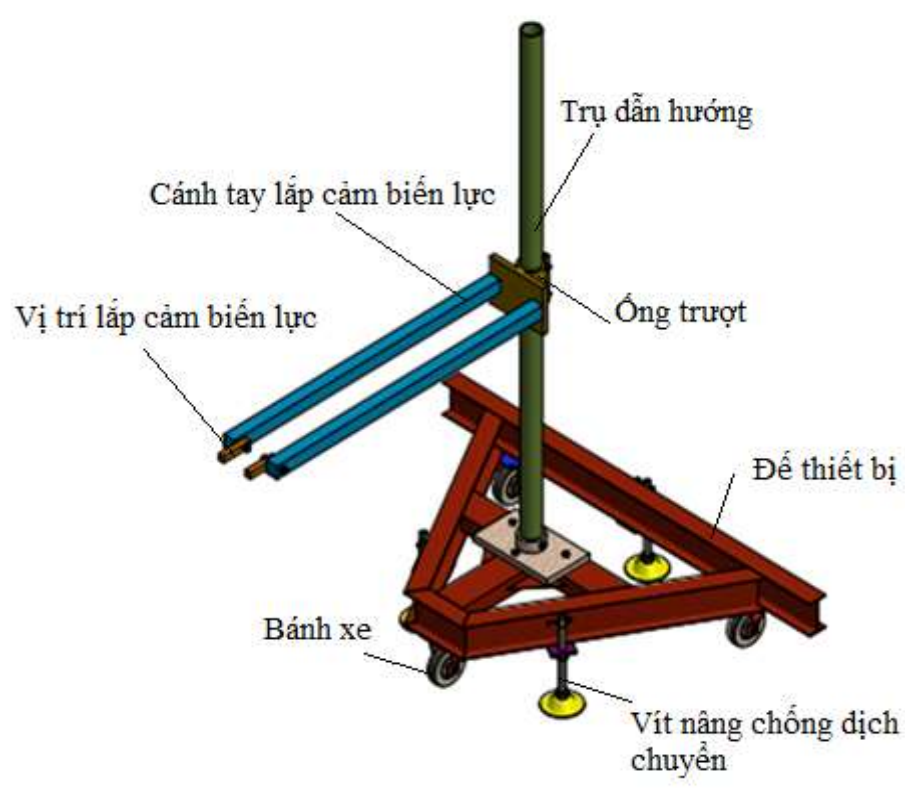

Hình 2: Sơ đồ thiết bị đo lực

\footnotetext{
1 - Động cơ; 5 - Bộ truyền đai;

2 - Khớp nối; 6 - Trục;

12 - Thanh rung;

3 - Trục;

7,8 - Bộ truyền xích $\mathrm{i}=1$

11- Trục rung;

4 - Quả lệch tâm; 9,10 - Bộ bánh răng $\mathrm{i}=1$; 14 - Bánh xe
} 


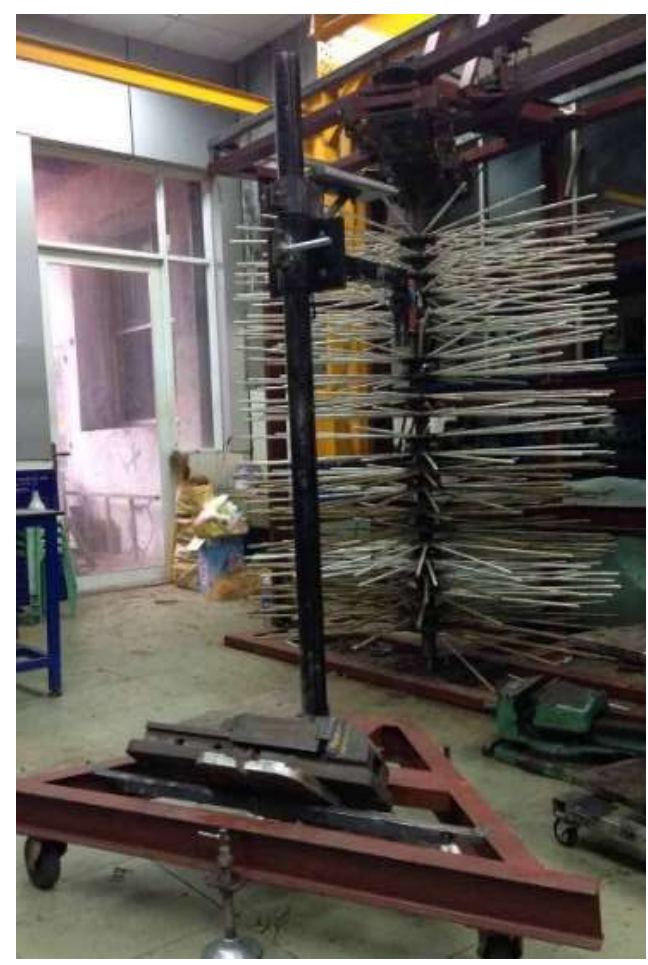

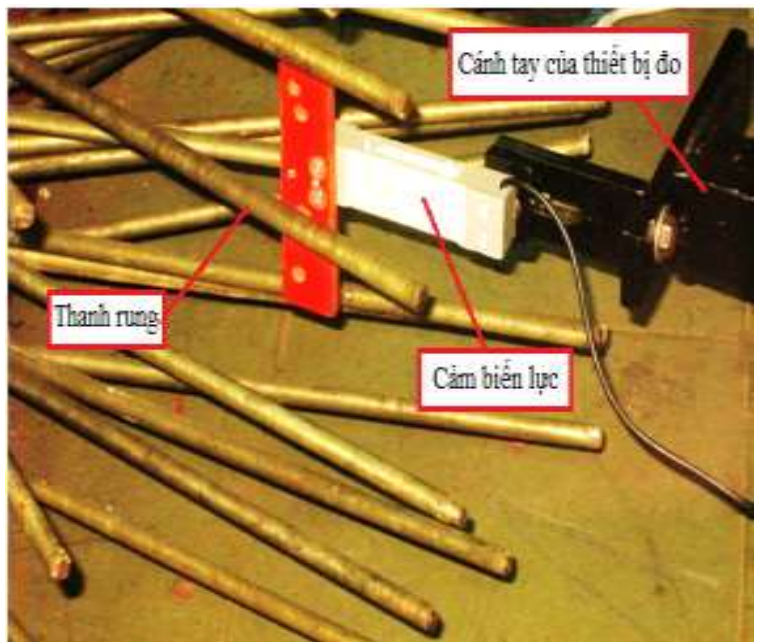

Hình 4: Lắp đặt cảm biến đo lực

Hình 3: Mô hình máy thu hoạch và thiết bị đo

Cảm biến lực đơn YZC 1B 20kgf được lắp đặt trên thiết bị đo lực, đóng vai trò như trái cà phê trên cây cà phê. Các thanh hái cà phê sẽ đập lên cảm biến như đập lên trái cà phê (Hình 2,3 và 4$)$.

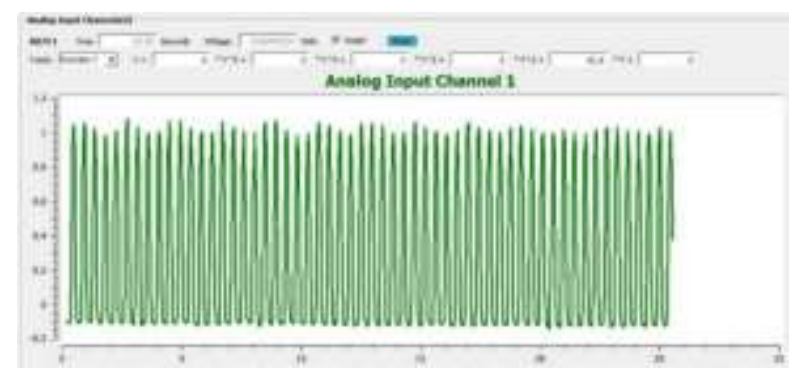

Hình 5: Tần số $10 \mathrm{~Hz}$, khối lượng lệch tâm 4,5 Kg

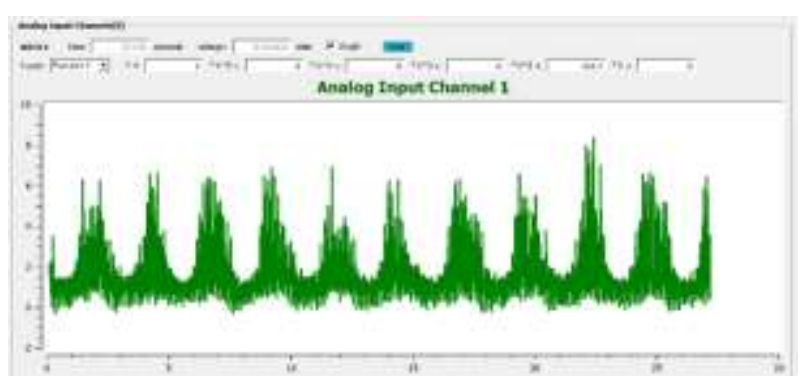

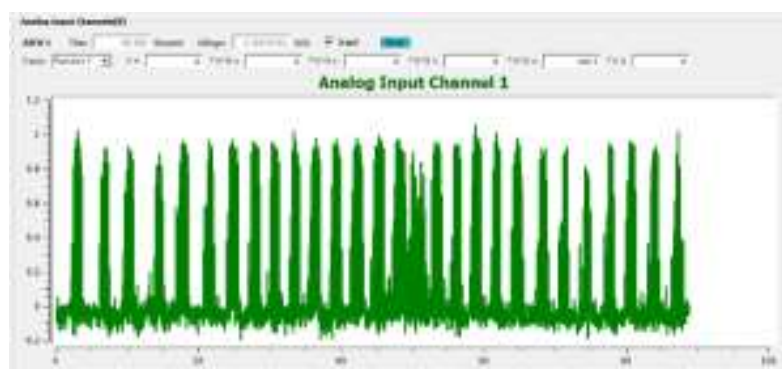

Hình 6: Tần số $20 \mathrm{~Hz}$, khối lượng lệch tâm 4,5 Kg

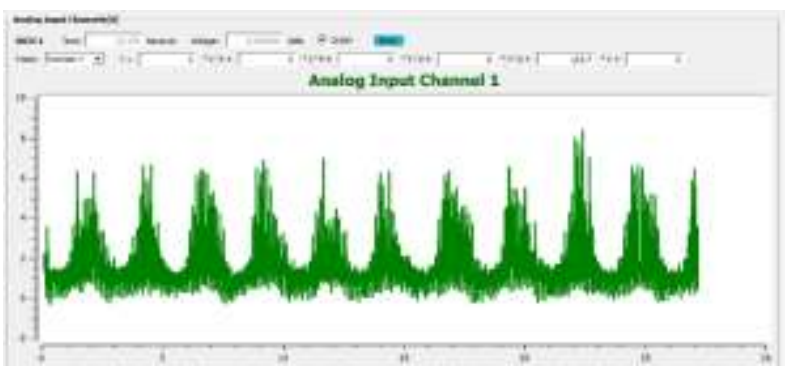


Hình 7: Tần số $30 \mathrm{~Hz}$, khối lượng lệch tâm 8,5 Kg

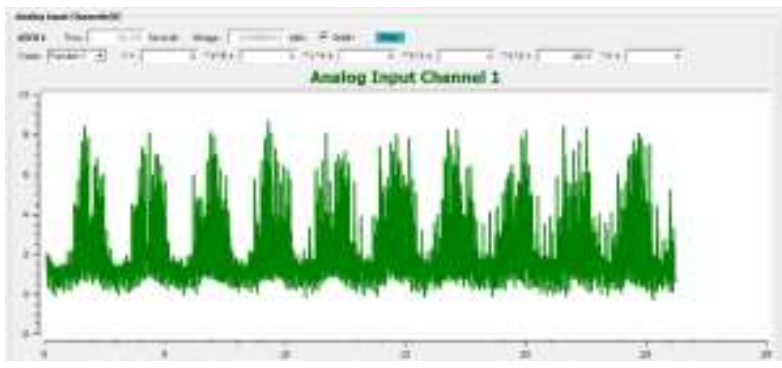

Hình 9: Tần số $33 \mathrm{~Hz}$, khối lượng lệch tâm 8,5 Kg

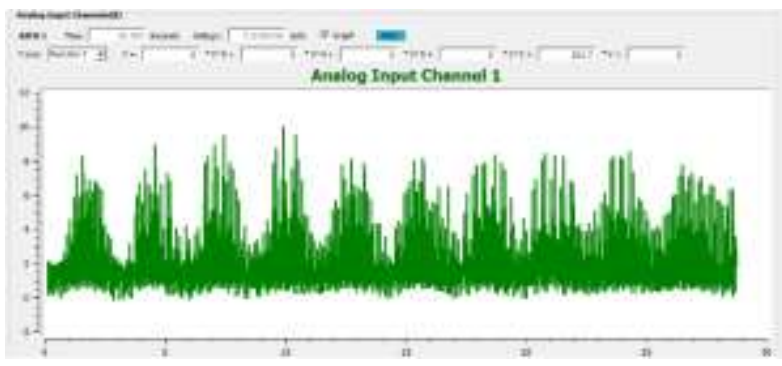

Hình 11: Tần số $35 \mathrm{~Hz}$, khối lượng lệch tâm 8,5Kg

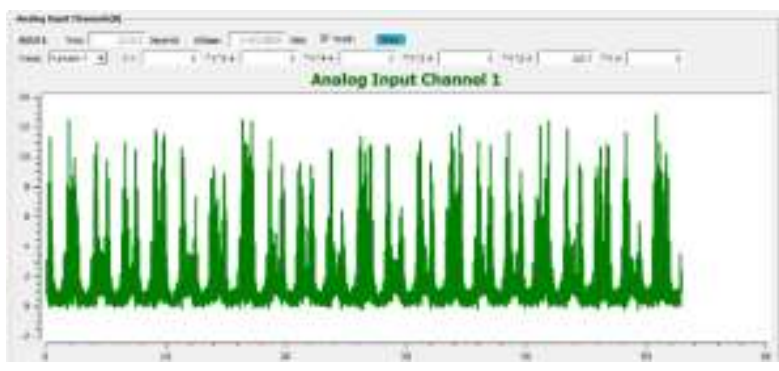

Hình 13: Tần số 42Hz, khối lượng lệch tâm $6 \mathrm{Kg}$

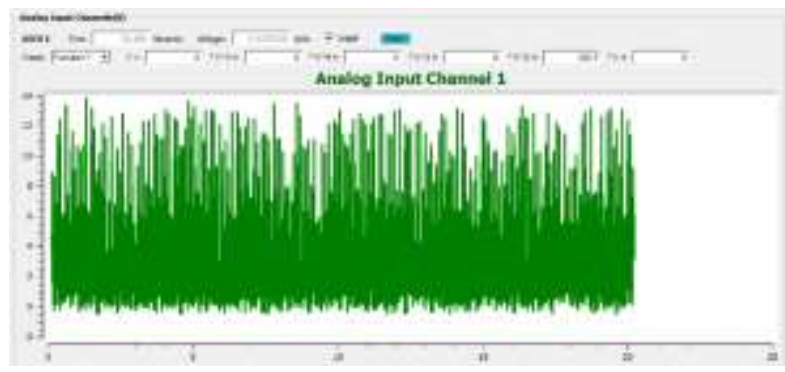

Hình 15: Tần số 45Hz, khối lượng lệch tâm $6 \mathrm{Kg}$
Hình 8: Tần số 32Hz, khối lượng lệch tâm 8,5 Kg

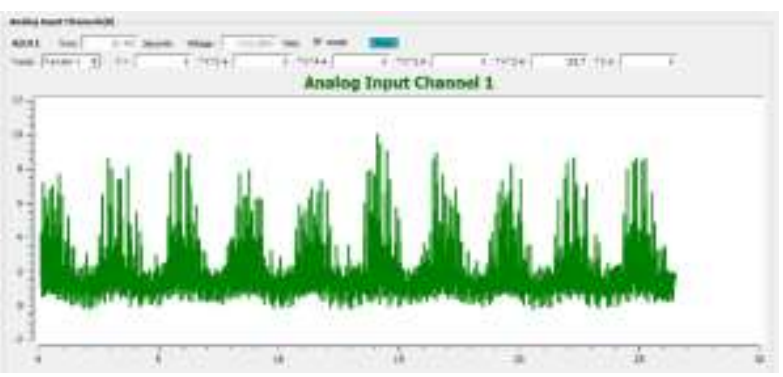

Hình 10: Tần số $34 \mathrm{~Hz}$, khối lượng lệch tâm 8,5Kg

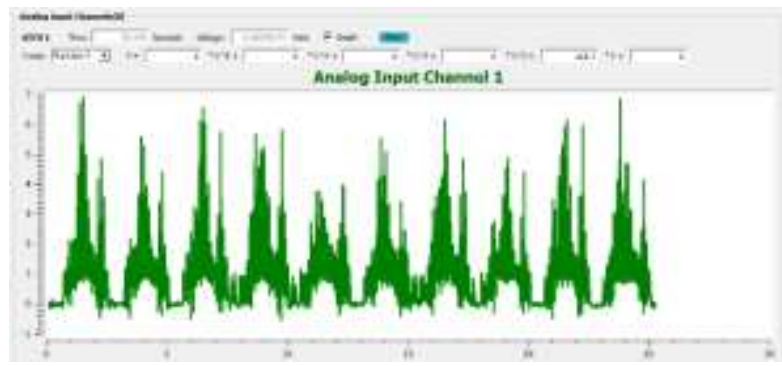

Hình 12: Tần số $40 \mathrm{~Hz}$, khối lượng lệch tâm $4.5 \mathrm{Kg}$

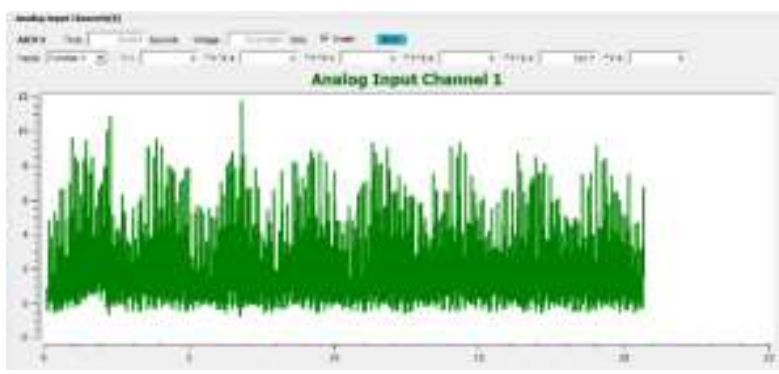

Hình 14: Tần số 44Hz, khối lượng lệch tâm 6 Kg

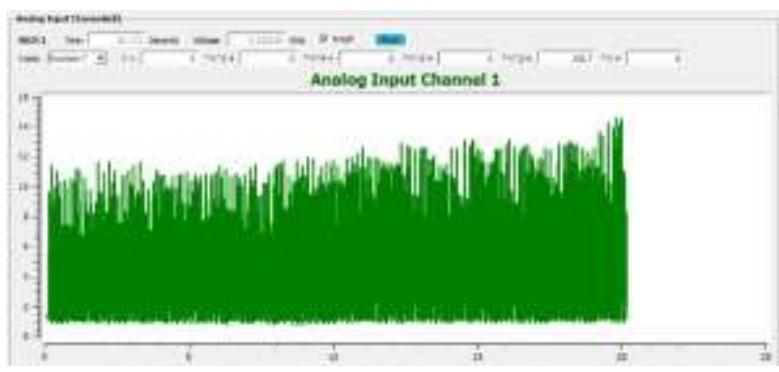

Hình 16: Tần số 47Hz, khối lượng lệch tâm $6 \mathrm{Kg}$

\section{KẾT QUẢ NGHIÊN CỨU VÀ THẢO LUẬn}

\section{1. Điều kiện thí nghiệm}

Trọng lượng quả lệch tâm trong hộp tạo dao động có 3 loại: $4,5 \mathrm{Kg}, 6 \mathrm{Kg}, 8,5 \mathrm{Kg}$ để lần lượt thay đổi trong quá trình thực nghiệm. Đồng thời thay đổi vận tốc quay của quả lệch tâm bằng cách thay đổi tốc độ động cơ qua biến tần, các tần số được chọn bao gồm: $30 \mathrm{~Hz}, 32 \mathrm{~Hz}, 33 \mathrm{~Hz}, 34 \mathrm{~Hz}, 35 \mathrm{~Hz}, 40 \mathrm{~Hz}, 42 \mathrm{~Hz}$, $44 \mathrm{~Hz}, 45 \mathrm{~Hz}$ và $47 \mathrm{~Hz}$. Lần lượt chọn từng khối lượng, mỗi khối lượng sẽ quay với 10 tốc độ của động cơ 
ứng với 10 tần số nói trên. Mỗi lần thí nghiệm sẽ làm 25 lần, lấy trung bình cộng lực của 10 đỉnh trong 1 lần thí nghiệm. Kết quả thể hiện biên độ lực và tần số (Hình 5 đến Hình 16) và được xuất ra bảng Excel. Sau đó qui hoạch giá trị trung bình cho mỗi loại kết hợp giữa trọng lượng quả lệch tâm và tần số.

\section{2. Ảnh hưởng của tần số đến lực thanh hái}

Chọn khối lượng lệch tâm cố định là $6 \mathrm{Kg}$, thay đổi lần lượt tần số từ $30 \mathrm{~Hz}$ đến $47 \mathrm{~Hz}$. Kết quả cho thấy khi tăng giá trị tần số lên đồng thời giữ nguyên khối lượng quả lệch tâm thì giá trị lực cũng tăng theo và ngược lại. Nghĩa là khi tăng số vận tốc của động cơ thì lực hái cũng gia tăng (Hình 17) và Công thức (1) với $\mathrm{R}^{2}=95,98 \%$.

$$
\mathrm{Y}=\frac{1}{-0.144+\frac{10.557}{\mathrm{X}}}
$$

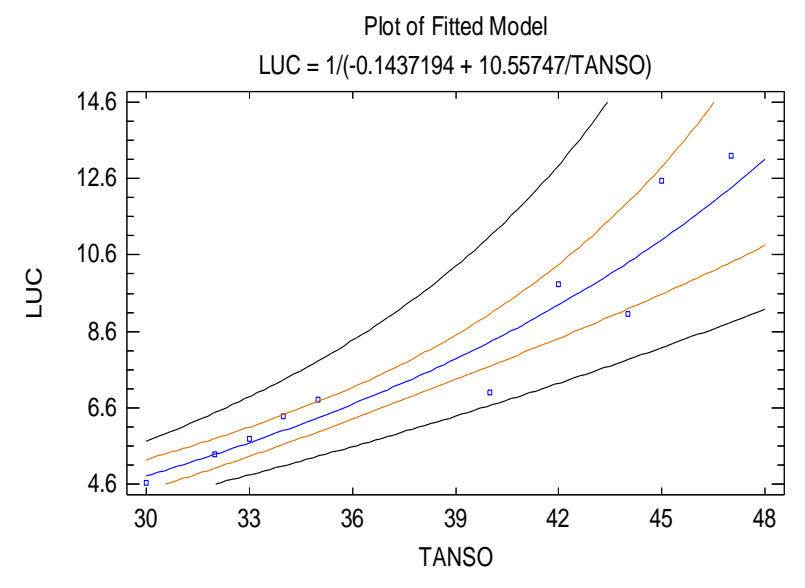

Hình 17: Quan hệ giữa tần số và lực

\section{3. Ảnh hưởng của khối lượng quả lệch tâm đến lực thanh hái}

Chọn tần số cố định là $34 \mathrm{~Hz}$, thay đổi khối lượng quả lệch tâm lần lượt là $4,5 \mathrm{Kg}$. Kết quả cho thấy khi tăng giá trị khối lượng quả lệch tâm lên đồng thời giữ nguyên tần số thì giá trị lực cũng tăng theo và ngược lại. Nghĩa là khi tăng khối lượng quả lệch tâm của cơ cấu rung thì lực hái cũng gia tăng (Công thức 2 và hình 18 ) với $R^{2}=99,99 \%$

$$
Y=\sqrt{28.755+0.378 X^{2}}
$$

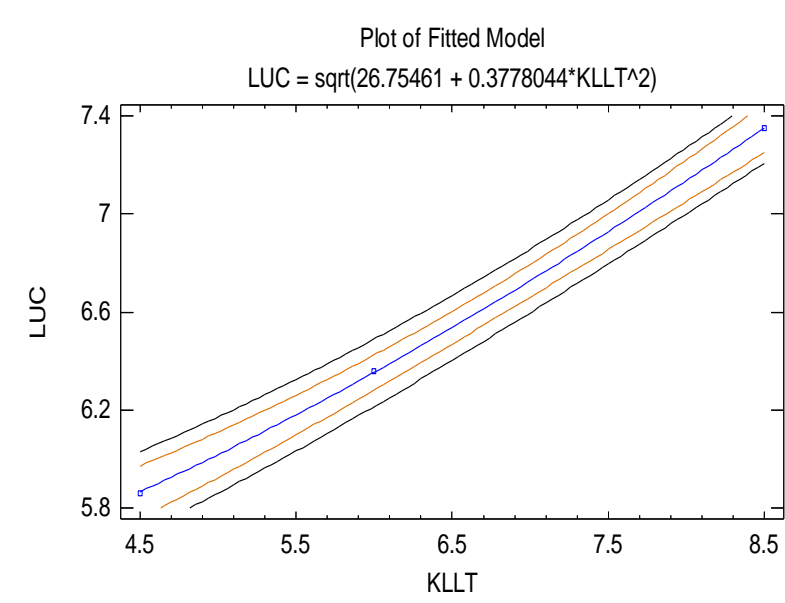

Hình 18: Quan hệ giữa khối lượng lệch tâm và lực 


\section{3. Ảnh hưởng của khối lượng quả lệch tâm và tần số đến lực thanh hái}

Nghiên cứu 2 yếu tố tác động gồm tần số và khối lượng bánh lệch tâm đến lực. Các tần số là $30 \mathrm{~Hz}$, $32 \mathrm{~Hz}, 34 \mathrm{~Hz}, 35 \mathrm{~Hz}, 40 \mathrm{~Hz}, 42 \mathrm{~Hz}, 44 \mathrm{~Hz}, 45 \mathrm{~Hz}, 47 \mathrm{~Hz}$ ứng với thay đổi khối lượng quả lệch tâm lần lượt là $4,5 \mathrm{Kg}, 6 \mathrm{Kg}$ và $8,5 \mathrm{Kg}$. Công thức (3) và hình (19) cho thấy khi tăng giá trị khối lượng quả lệch tâm và tần số thì giá trị lực cũng tăng theo và ngược lại. Nghĩa là khi tăng khối lượng quả lệch tâm và tần suất dao động của cơ cấu rung thì lực hái cũng gia tang với $\mathrm{R}^{2}=95,93 \%$.

$$
\mathrm{Y}=-9.542+0.448 X_{1}+0.383 X_{2}
$$

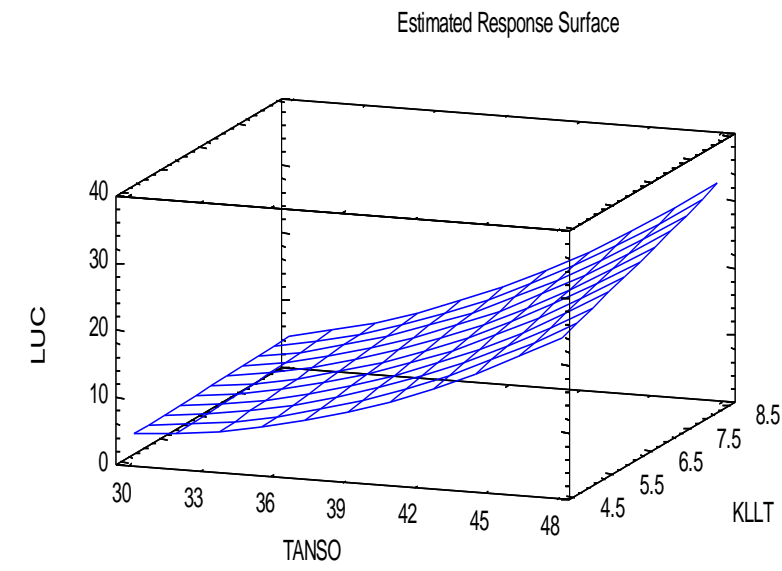

Hình 19: Quan hệ giữa tần số, KLLT và lực

\section{KẾT LUẬN}

Hiện nay tại Việt Nam chưa có một công trình nghiên cứu các thông số ảnh hưởng đến lực hái trái cà phê tại Việt Nam nói chung và tại tỉnh Đắk-Lắk nói riêng. Các nghiên cứu của các nhà khoa học trên thế giới đã công bố thì phần lớn là áp dụng nguyên lý dao động để tạo ra lực hái trái cà phê. Tuy nhiên, tại mỗi vùng miền trồng cà phê trên thế giới lực hái sẽ khác đi bởi nhiều yếu tố. Nghiên cứu này góp phần vào việc thu hoạch cà phê theo hướng công nghiệp cho tương lai tại tỉnh Đắk-Lắk từ đó có thể nhân rộng cho các vùng miền khác tại Việt Nam.

Qua thực nghiệm cho thấy mối quan hệ giữa các yếu tố như tần số rung các thanh hái, trọng lượng của các quả lệch tâm với lực hái được tạo ra của các thanh hái tỉ lệ thuận với nhau. Nghĩa là khi tăng tần số cho động cơ, hoặc tăng khối lượng của các quả lệch tâm lên thì lực trên các thanh hái cũng tăng theo. Điều này cho thấy ta có thể điều chỉnh lực hái phù hợp với cà phê các vùng miền khác nhau, hoặc cho các vườn cà phê có tỉ lệ trái chín khác nhau..

\section{LÒ̀I CẢM ƠN}

Bài báo được thực hiện trên kết quả nghiên cứu của đề tài nghiên cứu khoa học cấp cơ sở tại Trường Đại học Công nghiệp TpHCM với hợp đồng số: 71/HĐ-ĐHCN ký ngày12 tháng 4 năm 2017, mã số 171.1021.

\section{TÀI LIỆU THAM KHẢO}

[1]. D. O. M. a. P. K. Langa, "Principles of a Mechanical Shaker for Coffee Harvesting," the CIGR Ejournal., no. Agricultural Engineering International, January 2008

[2]. Dan-Kuhn, "Coffe-Production-Aussie-Style," [Online]. Available:

https://vi.scribd.com/document/211339432/Dan-Kuhn-Coffe-Production-Aussie-Style, April 2018.

[3]. V. M. Alexandrino, "Portable coffee harvesting machine". USA Patent US 4538405 A, 11121981. 
CỦA MÁY THU HOẠCH CÀ PHÊ TẠI TỈNH ĐẮK LẮK

[4] R. Scudder, "Coffee harvester". USA Patent US 4341062 A, 18718 July 1980.

[5]. F. L. S. e. al., "Analysis of the coffee harvesting process using an electromagnetic shaker," Acta Scientiarum. Agronomy, vol. 32, Sept.2010.

Ngày nhận bài: 30/05/2018

Ngày chấp nhận đăng: 09/06/2018 